\title{
An evaluation of brush biopsy in the diagnosis of peripheral pulmonary lesions
}

\author{
G. H. SMITH ${ }^{1}$ and A.J. N. WARRACK \\ Sheffield Cardio-thoracic Unit, Northern General Hospital, Sheffield, S5 7AU
}

\begin{abstract}
A method of abrasive biopsy of the peripheral bronchial tree is described. Forty-nine patients with peripheral pulmonary lesions have been investigated, and at bronchoscopy brush biopsies have been performed. In 13 cases a firm diagnosis of bronchial carcinoma was made and in nine patients atypical cells were reported. Two of the latter were found on further investigation to have had no carcinoma and one showed squamous metaplasia only on surgical biopsy. In nine patients a false negative result was obtained. These results suggest that the routine use of brush biopsy during bronchoscopy performed in the investigation of peripheral pulmonary lesions helps to increase the accuracy of diagnosis.
\end{abstract}

The diagnosis of bronchial carcinoma is easily made when the lesion affects those portions of the bronchial tree which are visible through a bronchoscope. Lesions more distal, however, present more difficult problems, and in spite of other investigations, such as bronchography and sputum cytology, there remain a number of peripheral lesions which are diagnosed only on radiographic appearances. Subsequent thoracotomy and lung resection show that some of these lesions are not malignant. In an effort to reduce the number of such cases we have performed brush biopsies of the peripheral bronchial tree in 49 patients under investigation for peripheral pulmonary lesions thought to be neoplastic in origin.

\section{METHODS AND MATERIALS}

We found that a strong easily passed 'brush' could be made by extracting a suitable cylinder of material, 2.5 $\times 0.5 \mathrm{~cm}$, from an acrylic baby sponge using a No. 2 cork borer (Fig. 1) and mounting it on a 10-cm length of malleable wire. Nichrome $25 \mathrm{swg}(0.0048 \mathrm{in})$ similar to that used as a substitute for 'platinum loops' in the bacteriology department was found to be suitable. The mounting is simply done by heating the wire over a Bunsen burner and laying the wire gently along the length of the cylinder of sponge. The heat allows

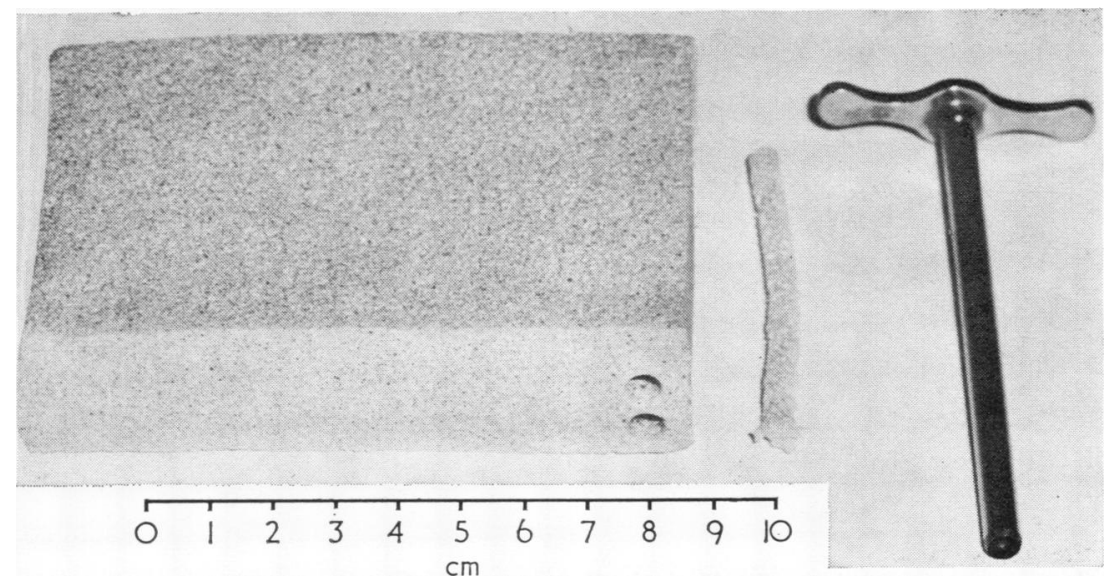

FIG. 1. Materials for construction of 'sponge'. 


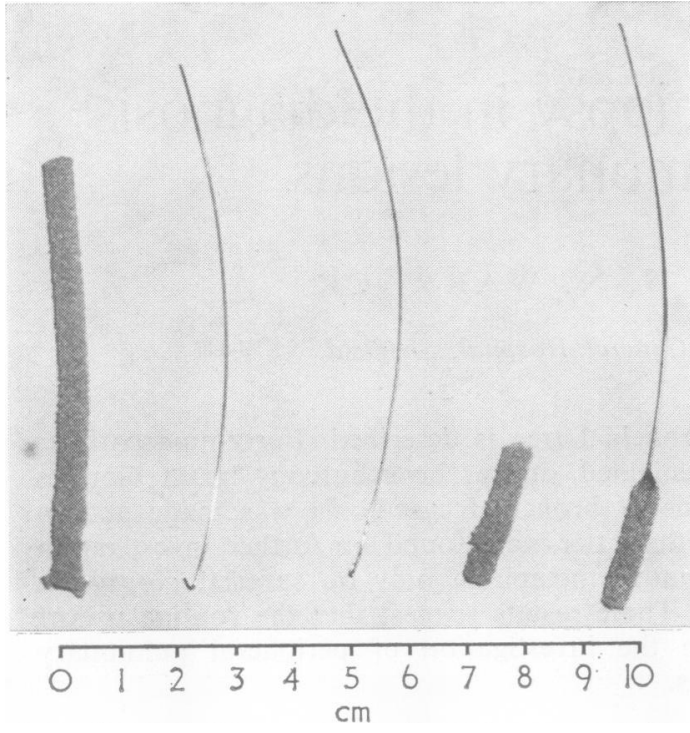

FIG. 2. Shows method of construction of bronchial brush.

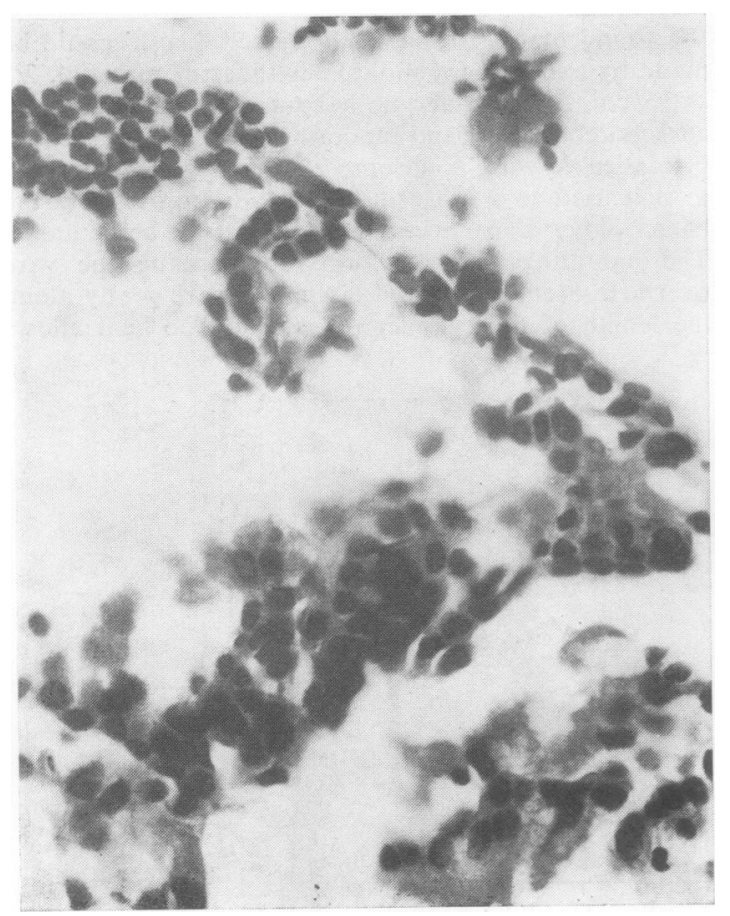

FIG. 3. Sponge histology showing presence of atypical cells (H. and E. $\times 550$ ). the wire to sink in the centre, and on cooling it is firmly sealed into the melted and resolidified sponge (Fig. 2). Sterilization is carried out by ethylene oxide exposure in a plastic envelope.

The finished product is similar to a stiff pipe cleaner. $\nRightarrow$ The sponge is fastened to the peripheral end of $\vec{\circ}$ bronchoscopic foreign body forceps. The wire is wound around the end of the instrument in such a way as not to leave a sharp projection. Approximately $3 \mathrm{~cm}$ of the brush protrudes beyond the end of the forceps. The brush is passed under bronchoscopic control into the mouth of the relevant bronchus. It is then advanced as far as possible, twisted, and withdrawn. In no case was excessive bleeding produced or was the brush 'lost' distally. After withdrawal, the entire brush is placed in formol saline in a Universal container.

In the laboratory no attempt is made to make a smear. The sponge is removed from the wire by gentle $C$ traction with forceps and processed automatically. A paraffin block is made. Sections are cut at $6 \mathrm{~m} \mu$, mounted on ordinary glass slides, and stained by haematoxylin and eosin.

The microscope slides made from each brush were examined by one of us (A.J.N.W.) using an ordinary light microscope The sponge appears as a fine pale blue network of acrylic fibre in the interstices of which not only individual cells, but fragments of mucosa,

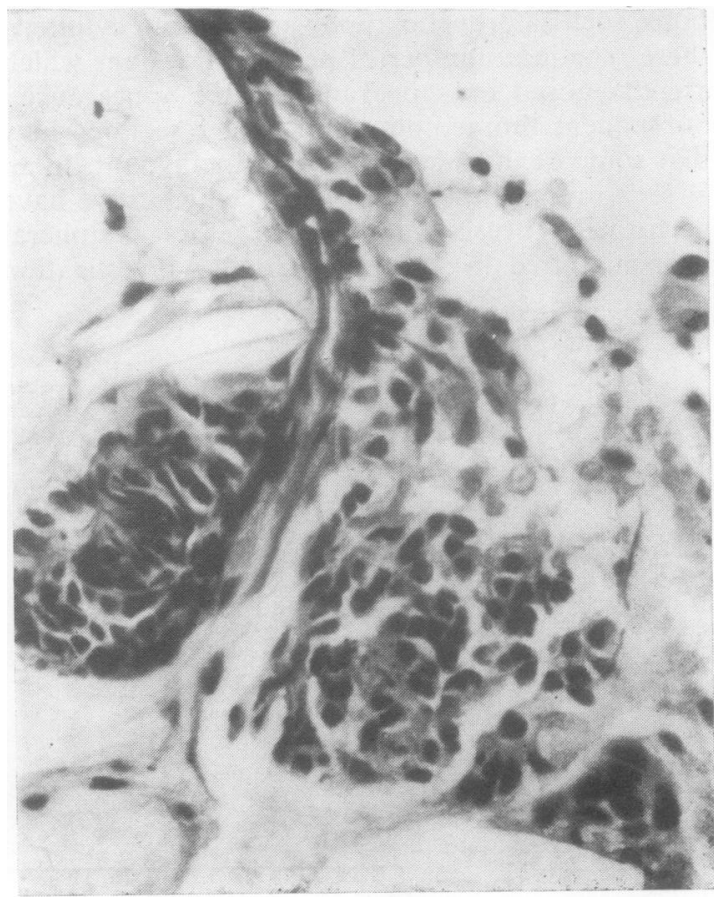

FIG. 4. Fragment of squamous carcinoma in sponge (H. and $E . \times 550)$. 
inflammatory debris, and sometimes atypical cells or new growth can be seen (Figs. 3, 4, and 5). The cells were assessed and reported. The report was confined to (a) negative or inflammatory, (b) atypical, and (c) carcinoma cells.

Our criteria for reporting a cell as atypical are simple and follow accepted cytological practice (Warrack, 1966). They include alteration in the nuclear cytoplasmic ratio, irregular distribution of nuclear chromatin, and alteration in the size, shape, and polarity of the nucleus (Fig. 3).

The diagnosis of frank carcinoma was made only when actual fragments of malignant tissue could be identified. In these cases it was possible to distinguish between the various types of bronchogenic carcinoma (Figs. 4 and 5). In those cases where an operation had been performed a surgical specimen had been obtained and examined histologically in every case. Those patients who had not been operated on were reviewed by one of us (G.H.S.).

Finally, the results of the brush biopsies were compared with the ultimate diagnosis of the pulmonary lesions and with the ultimate fate of the patient.

\section{RESULTS}

During the nine-month period, 49 patients were seen who were suitable for inclusion in this report.

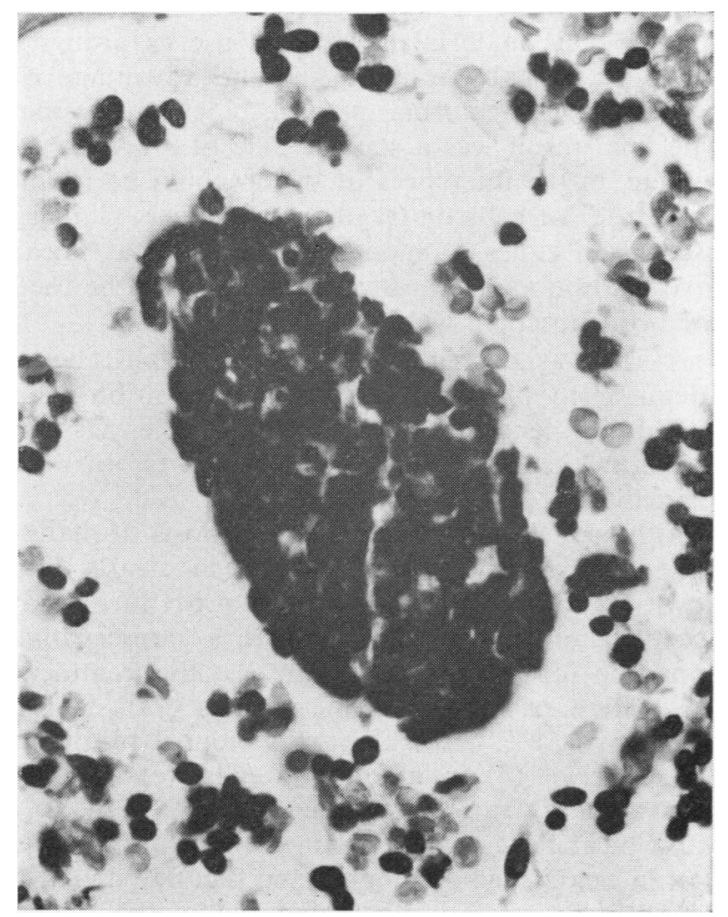

FIG. 5. Fragment of 'oat-celled' carcinoma in sponge (H. and E. $\times 550)$.
At review the minimum period of follow-up was three months and the maximum one year, with a mean of $7 \cdot 2$ months.

We have used this method of abrasive biopsy in all patients with peripheral pulmonary lesions who have been referred to our bronchoscopy clinic during a nine-month period. By definition, none of these patients had direct evidence of bronchial neoplasm at bronchoscopy. Each patient also had sputum examined for the presence of malignant cells and tubercle bacilli on at least three occasions. In many patients, particularly those with segmental collapse, bronchography was also performed.

Fragments of carcinomatous tissue were identified in the brush in 13 patients. A positive bronchial biopsy was obtained from the relevant bronchus in five of these patients in spite of mucosa which appeared normal, and in one patient malignant cells were found in the sputum. Thus, the result of the brush biopsy was diagnostic in seven patients in this group. Seven patients underwent surgery and lung resection. In one of these, carcinoma in situ was identified, and in the remaining six, invasive carcinoma was found. Six patients did not undergo surgery because of poor respira-

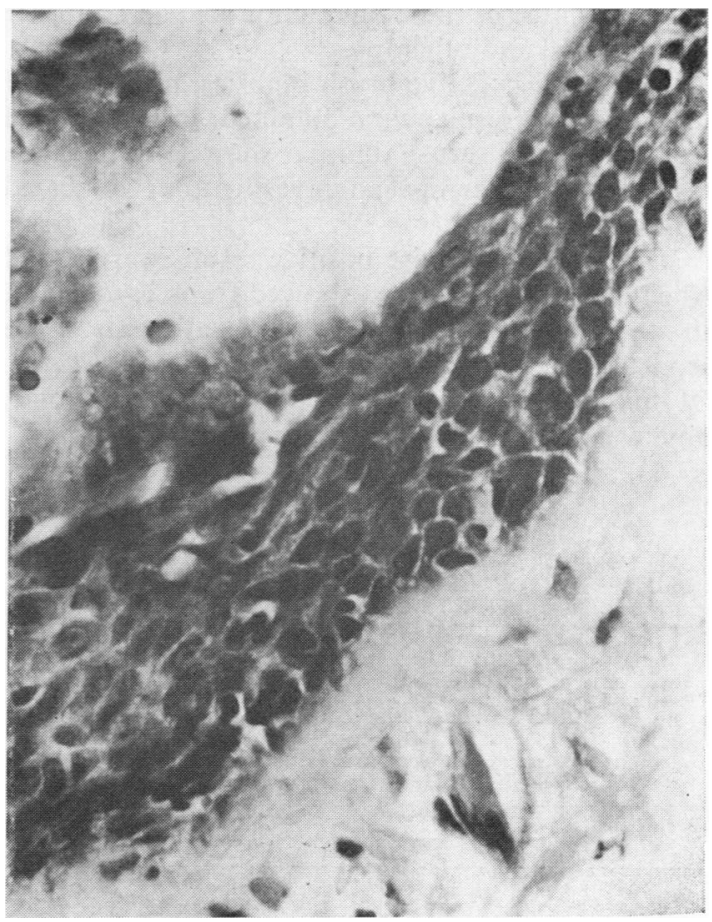

FIG. 6. Surgical biopsy of bronchus from same patient as in Fig. 3; early carcinoma in situ ( $H$. and $E . \times 550)$. 
tory reserve and four have subsequently died. Two received radiotherapy.

Atypical cells were found in the bronchial brush in nine patients. Two were not submitted to surgery because of rapid radiological resolution of the pulmonary lesion and on follow-up were found to have normal chest radiographs. Six patients were treated by operation and lung resection. Four of this group were found to have carcinoma in the resected specimen; in one case this was found to arise adjacent to a tuberculoma. One patient had carcinoma in situ (Fig. 6) and one patient had no evidence of neoplasm. One patient in this group was lost to follow-up and was excluded.

Twenty-seven brush biopsies showed neither frank carcinoma nor atypical cells. Three of this group were unavailable to follow-up and are excluded. Fourteen patients were reviewed in the outpatient department and all showed resolution of the lung shadows on repeated radiographs. Another six patients were reviewed in a similar manner and, because of progression in the size of the lung shadow, were operated upon. In five, bronchial carcinoma was found, and a solid fibrotic lesion in the sixth. Four patients with poor respiratory function showed an increase in the pulmonary shadow. Three of these have since died and another has received radiotherapy.

Thus in 27 negative brush biopsies, nine cases of false negative results were obtained. In no case did we find that a brush biopsy showed a negative result when other special investigations indicated carcinoma.

In summary, no false positive results were found when the bronchial brush showed frank carcinoma. In the nine cases where 'atypical' cells were reported three could be classified as false positives. Of the 27 cases of negative bronchial brushings, nine were found to be false negative results.

\section{T A B L E}

COMPARISON OF BRUSH BIOPSY RESULT AND FINAL DIAGNOSIS IN THE 49 PATIENTS UNDER REVIEW

\begin{tabular}{|c|c|c|c|c|c|c|}
\hline \multirow{2}{*}{$\begin{array}{c}\text { Result of } \\
\text { Brush } \\
\text { Biopsy }\end{array}$} & \multicolumn{2}{|c|}{$\begin{array}{l}\text { Method of } \\
\text { Confirmation of } \\
\text { Carcinoma }\end{array}$} & \multicolumn{2}{|c|}{$\begin{array}{l}\text { No Carcinoma } \\
\text { Present }\end{array}$} & \multirow{2}{*}{$\begin{array}{l}\text { Lost to } \\
\text { Follow- } \\
\text { up }\end{array}$} & \multirow{2}{*}{ Total } \\
\hline & $\begin{array}{l}\text { Surgical } \\
\text { Specimen }\end{array}$ & $\begin{array}{l}\text { Final } \\
\text { Clinical } \\
\text { Course }\end{array}$ & $\begin{array}{c}\text { Surgical } \\
\text { Specimen }\end{array}$ & $\begin{array}{l}\text { Final } \\
\text { Clinical } \\
\text { Course }\end{array}$ & & \\
\hline $\begin{array}{c}\text { Carcinoma } \\
\text { cells }\end{array}$ & 7 & 6 & 0 & 0 & 0 & 13 \\
\hline $\begin{array}{r}\text { Atypical } \\
\text { cells }\end{array}$ & 5 & 0 & 1 & 2 & 1 & 9 \\
\hline$\underset{\text { cells }}{\text { Normal }}$ & 5 & 4 & 1 & 14 & 3 & 27 \\
\hline
\end{tabular}

\section{DISCUSSION}

The diagnosis of pulmonary lesions beyond the range of the bronchoscope by the use of aspiration or brush techniques has been described by several workers. Craver (1940) discussed the use of aspiration biopsy and sputum examination and these procedures are now in general use (Osborn, 1953; Graham, 1963; Philps, 1964).

The interpretation of cytological smears from the respiratory tract, however, presents difficulties (Tsuboi, 1959).

In recent years, several workers have described methods by which, without the use of surgical biopsy, more representative material can be obtained from the respiratory tract. MacLean (1958) described a bronchial abrasion microbiopsy instrument, and Fennessy (1966) reported a technique by which a radio-opaque catheter was inserted into the segmental bronchus under radiological control, allowing small brushes to be passed through it. This allowed material for cytologic and bacteriological examination to be obtained.

Cinberg (1951), with the object of examining material more representative than was usually obtainable in a cervical smear, devised a 'brush' technique using a swab constructed of acrylic sponge. This material, in current use as ordinary domestic or baby sponge, had the advantage of being capable of normal paraffin block processing. The final result was a stained slide of a section of sponge, in the interstices of which could be found aggregates of cells or fragments of tissue. Cinberg used small cubes of sponge for his cervical smear investigation and indicated that they could be used for bronchoscopic work.

A cube as described by Cinberg, whilst being adequate to pick up cells in the main bronchi, would not lend itself to easy and safe passage through the more inaccessible parts of the bronchial tree.

Although the criteria for the diagnosis of malignant cells in the sputum have been clearly laid down by many workers, and the procedure is an accepted one, we have adopted a conservative approach for the cogent reason that the treatment for malignant disease of the lung is both drastic and irrevocab'e, hence the expression of results as (a) negative, (b) inflammatory cells, (c) atypical cells, and $(d)$ frank carcinoma.

Atypical cells seem to occur in two types of case, first in established carcinoma and secondly in cases where there is established squamous metaplasia of the bronchial mucosa with either basal dysplasia or established carcinoma in situ analogous to that 
found in the uterine cervix (Fig. 6). As stated by Osborn (1953) in cases of lesions of the uterine cervix, only histological examination of a true surgical biopsy can show whether the lesion is invasive or not. When atypical cells rather than fragments of frank carcinomatous debris are found in a sponge biopsy we make no attempt to differentiate between invasive carcinoma and a possibly premalignant picture of squamous metaplasia or carcinoma in situ (Graham, 1963). Similarly, we have not found it expedient or useful to identify dyskaryotic cells and diagnose dysplasia as opposed to carcinoma in situ.

In assessing the criteria to be adopted before embarking on radical surgical treatment in the management of bronchogenic carcinoma, one of us (G.H.S.) considers four main points: the general clinical condition, the chest radiograph, the bronchial biopsy, and the bronchial sponge biopsy. A firm diagnosis of carcinoma can be made on a chest film and positive bronchial biopsy and also on a chest film and positive sponge biopsy when frank carcinoma is seen; when atypical cells are reported in the sponge biopsy this is an indication for further investigation, such as bronchography. In the case of isolated peripheral lesions, however, bronchography has been found to supply useful information only rarely, and in these circumstances the presence of atypical cells in the brush biopsy should be regarded as a reason for surgery.

The results clearly show that bronchial brush biopsy is of use in the diagnosis of peripheral pulmonary lesions. Together with the results of all other investigations, it has helped us to avoid a number of major surgical procedures in patients who have not had malignant disease, or has indicated a need for surgery in patients who would have been operated on only after much delay. We will rely increasingly on the result of the sponge biopsy.

We are indebted to $\mathrm{Mr}$. C. A. Lambourne for both making and processing the sponges.

\section{REFERENCES}

Cinberg, B. L. (1951). Cancer of the cervix. Diagnosis by sponge biopsy. N.Y. Med., 7, no. 2; p. 18.

Craver, L. F. (1940). Diagnosis of malignant lung tumors by aspiration biopsy and sputum examination. Surgery, 8, 947.

Fennessy, J. J. (1966). Bronchial brushing in the diagnosis of peripheral lung lesions. Amer. J. Roentgenol., 98, 474.

Graham, R. M. (1963). The Cytologic Diagnosis of Cancer, 2nd ed. pp. 85, 206, and 232. W. B. Saunders, Philadelphia.

MacLean, K. S. (1958). Bronchial abrasion microbiopsy instrument. J. Amer. med. Ass., 166, 2160.

Osborn, G. R. (1953). Applied Cytology, pp. 65 and 68. Butterworth, London.

Philps, F. R. (1964). A Short Manual of Respiratory Cytology. Pitman Medical Publishing Company, London.

Tsuboi, E. (1959). Studies on early diagnosis of lung cancer, especially cytologic diagnosis of bronchial cells obtained by direct scrape off method. Nippon Acta radiol., 19, 1029.

Warrack, A. J. N. (1966). Exfoliative cytology and the diagnosis of carcinoma of the cervix. Indian Practit., 19, 97. 